\title{
Groundwater Potential Evaluation of College of Engineering, Afe Babalola University, Ado-Ekiti, Southwestern Nigeria
}

\author{
Ogundana A.K ${ }^{1, *}$, Talabi A. $\mathrm{O}^{2}$ \\ ${ }^{1}$ Department of Geology, Afe Babalola University, Ado-Ekiti \\ ${ }^{2}$ Department of Geology, Ekiti State University, Ado-Ekiti \\ *Corresponding author: dejiogundana@gmail.com
}

Received January 03, 2014; Revised February 28, 2014; Accepted March 11, 2014

\begin{abstract}
Availability of water for daily activities has constituted serious challenge at the College of Engineering, Afe Babalola University, Ado-Ekiti. Hence, geophysical study of the College was conducted to investigate its groundwater potential with a view to proffer solution to water availability in the study area. Profiling and Vertical electrical sounding methods were employed using Dipole - Dipole and Schlumberger configuration respectively. Eight points were sounded along three traverses and one profile was occupied. Five different subsurface lithologic units were established namely; lateritic topsoil, sandy-clay, weathered basement, fractured basement and, fresh basement. The curve types range between simple $\mathrm{K}, \mathrm{H}$ to complex HA, HK and KH. The topsoil, sandy-clay and weathered basement materials are characterised with relatively low resistivity values while the fresh basement materials are characterized with high resistivity values. The average resistivity and thickness values for the topsoil are $178 \Omega \mathrm{m}$ and $1.0 \mathrm{~m}$ respectively. Sandy-clay was encountered in six locations with average resistivity and thickness values of $23 \Omega \mathrm{m}$ and $7.0 \mathrm{~m}$ respectively. Weathered basement was encountered in six locations with average resistivity and thickness values of $231 \Omega \mathrm{m}$ and $8.0 \mathrm{~m}$ respectively. Fractured basement was encountered in four locations with average resistivity and depth to the top of fracture values of $294 \Omega \mathrm{m}$ and $18.0 \mathrm{~m}$ respectively. Basement is relatively shallow in the study area, it was encountered in three locations and the average resistivity and depth values to the top of basement are $1000 \Omega \mathrm{m}$, and $11.0 \mathrm{~m}$ respectively. Overburden thickness was established in six locations with an average value of $11.0 \mathrm{~m}$. The combination of overburden materials with the fractured basement constitutes aquiferous units within the study area. The groundwater potential of the area is rated as medium with VES 2 and 5 more promising.
\end{abstract}

Keywords: groundwater potential, profiling, vertical electrical sounding, average resistivity

Cite This Article: Ogundana A.K, and Talabi A. O, "Groundwater Potential Evaluation of College of Engineering, Afe Babalola University, Ado-Ekiti, Southwestern Nigeria.” American Journal of Water Resources, vol. 2, no. 1 (2014): 25-30. doi: 10.12691/ajwr-2-1-4.

\section{Introduction}

Afe Babalola University Ado-Ekiti has being described as the fastest growing private university in Nigeria and in its bid to keep up the unprecedented growth rate and remain a pace setter in reformatory education has taken another giant stride in constructing the largest college of engineering in Nigeria today. The enviable pace of infrastructural development among other factors is attracting more and more people into the university and the population keeps increasing at a steady rate. As population increases, the need for clean water supply increases thus posing a challenge in a typical basement environment with little groundwater potential.

The safest kind of water supply is groundwater with a natural protection against pollution by the covering layers, only minor water treatment is required. Groundwater exploration reports around Ado-Ekiti suggest low fracture in most part of this state capital. This results in low yield in most of the boreholes own by private individual and public.

Several workers such as Dutcher and Garret (1965), Clerk (1985), Olorunfemi and Olorunniwo (1985), Olorunfemi (1990), Olayinka and Olorunfemi (1992)Olorunfemi and Olayinka (1992), Olorunfemi and Fasuyi (1993), Oladipo et al, (2005) Olayinka and Weller (1993), Rehil and Birk (2010), Ojo et al, (2011), Talabi (2013) have carried research in various aspect of groundwater exploration/investigation, evaluation and structural delineation using geophysical methods in several location within the basement complex terrain around the world.

Afe Babalola University located in Ado Ekiti is not exempted from the challenge of low groundwater availability resulting from complex geology of this area, hence, the need to source for additional means to complement the existing water supply for the ever- 
increasing population of the University community. There is need to investigate and evaluate the groundwater potential of the newly constructed college of engineering within the campus for improved water supply. The university has spent fortunes in sinking boreholes to ensure that the daily demand for potable water on the campus is met, but the ever increasing population growth of the university community with the attendant increase in water requirement suggest the need for further groundwater potential evaluation of the campus. However, groundwater exploration in the basement aquifers posed a serious challenge resulting from complexity of rocks and minerals and their attendant heterogeneous grain size distribution. Olayinka and Olorunfemi (1992) emphasized the need to conduct a surface geophysical survey such as Vertical Electrical Resistivity Sounding in identifying the localized aquiferous zones before siting boreholes. Electrical resistivity method has been used extensively in groundwater investigation especially in the basement complex terrains (Grant and West, 1965, Olorunfemi and Olorunniwo, 1985. Olorunfemi, 1990. Olorunfemi and Olayinka, 1992). Recently, Ademiluwa and Eluwole 2013 evaluated groundwater potential of some part of the university and concluded that weathered basement anf fractured basement constitute the main aquifer types within the study area based on their layer thicknesses and resistivity. This study therefore aims at assessing the groundwater potential of the college with attention on the delineation of the fracture system, overburden thickness and lithological variation across the terrain.

\section{Location and Geology of the Study Area}

\subsection{Location}

Afe Babalola University is located in Ado-Ekiti along Ijan road, opposite The Federal Polytechnics. The study college is located at the north-western part of the University campus opposite Alfa Belgore Hall and adjacent female hall of residence. It lies at longitudes 5०18'25.87"E and latitudes 7³6' 23.82"N (Figure 1). The terrain in the study area is gently undulating, with topographic elevation ranging from $350 \mathrm{~m}$ to $370 \mathrm{~m}$ above sea level.

Ado Ekiti is underlain by crystalline rocks made of Older granite, Migmatite and Charnockites with little or no fracture in most location and shallow overburden.



Figure 1. Aerial Photo of the Study Location

\subsection{Climate, Geology and Hydrogeology of The Area}

The area is situated within the tropical rain forest region, with a climate characterized by dry and wet seasons. Average annual rainfall in this area is $1300 \mathrm{~mm}$, with average wet days of about 100 . The annual temperature varies between $18^{\circ} \mathrm{C}$ to $34^{\circ} \mathrm{C}$.

The study area lies within the basement complex of south-western Nigeria and is made up of; older granite, Migmatite and Charnockites. The overburden is relatively shallow within the study area with average of $11 \mathrm{~m}$. The groundwater is found within the overburden and fractured basement while the area is drained by the river Ogbese which flow SW-NE direction.

The basement complex rocks are poor aquifers as they are characterized by low porosity and negligible permeability, resulting from their crystalline nature, thus availability of groundwater resource in such areas can only be attributed to the development of secondary porosity and permeability resulting from weathering and fracturing.

\section{Methodology, Data acquisition and Interpretation}

A reconnaissance survey of study college was carried out for site familiarization and planning. This was followed with geophysical investigation of the college and environs. Geophysical methods are indirect site investigation techniques and predominantly non-intrusive. Two methods namely Resistivity Sounding and Resistivity Profiling were adopted. Soil resistivity meter (PASI) was used for the geophysical tests. It is highly reliable and reproducible.

Resistivity sounding was adopted in resolving resistivity variation with depth, thus sounding helped in delineating the various subsurface lithological units, hydrogeological significance and the protective capacity 
or vulnerability of the subsurface layers to possible pollution. Resistivity profiling was adopted in resolving horizontal resistivity variation in this study, hence profiling helped in establishing the lateral continuity of the various subsurface lithological units.

\section{Results and Discussions}

\subsection{Vertical Electrical Sounding}

A total of 8 VES locations across 3 traverses were spread over the study area (Figure 1 ). The processed data were interpreted, resulting curve types were assessed, existing subsurface lithologic units were established, and the geoelectric properties of the various subsurface layers were used in delineating the aquiferous units in the study area. The results are presented in the form of table (Table 1), geoelectric curves (Figure 3 ) and sections (Figure 4a \& Figure 4b).

Five different subsurface lithologic sequences were established namely; lateritic topsoil, sandy-clay, weathered basement, fractured basement and, basement. The curve types range between simple $\mathrm{H}, \mathrm{K}, \mathrm{HA}, \mathrm{KH}$ and HK. The topsoil, sandy-clay and weathered basement materials are characterised with relatively low resistivity values while the basement materials are typified with high resistivity values. A summary of the results of interpretation, on which the following findings were hinged, is shown in Table 1.



Figure 2. Geology Map of the Study Area

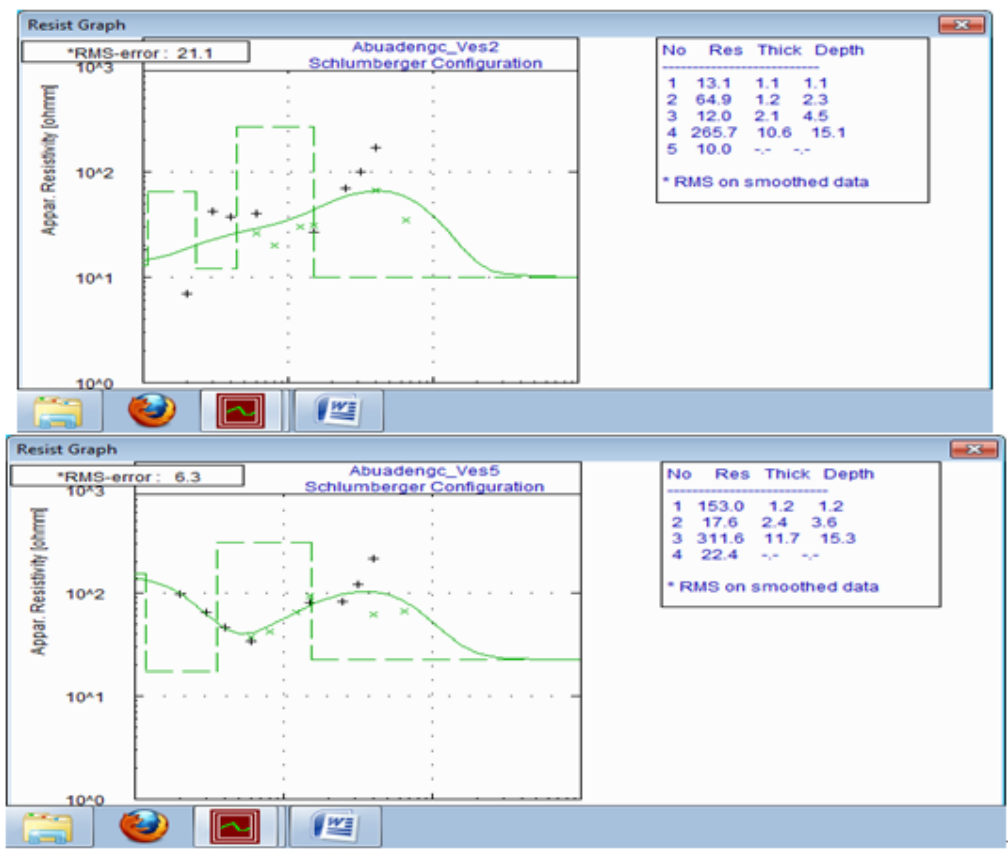

Figure 3. Typical Geoelectric curves from data interpretations 
Table 1. Correlation Table

\begin{tabular}{|c|c|c|c|c|c|c|c|c|}
\hline VES POINT & & 1 & 2 & 3 & 4 & 5 & 6 & 70 \\
\hline VES FUIIVI & & 1 & 2 & 3 & & 5 & 6 & 78 \\
\hline CURVE TYPE & & $\mathrm{H}$ & $\mathrm{K}$ & $\mathrm{KH}$ & HA & HK & HA & K K \\
\hline \multicolumn{9}{|l|}{ LITHOLOGY } \\
\hline \multirow{4}{*}{ TOP SOIL } & TOP & 0 & 0 & 0 & 0 & 0 & 0 & 00 \\
\hline & BASE & 2 & 2 & 2 & 1 & 1 & 1 & 11 \\
\hline & THICKNESS & 2 & 2 & 2 & 1 & 1 & 1 & 11 \\
\hline & $\Omega \mathrm{m}$ & 73 & 65 & 302 & 103 & 153 & 42 & 560128 \\
\hline \multirow{4}{*}{ SANDY-CLAY } & TOP & 2 & 2 & 2 & 1 & 1 & 1 & -- \\
\hline & BASE & 19 & 5 & 11 & 9 & 4 & 4 & -- \\
\hline & THICKNESS & 17 & 3 & 9 & 8 & 3 & 3 & -- \\
\hline & $\Omega \mathrm{m}$ & 23 & 12 & 19 & 46 & 18 & 20 & -- \\
\hline \multirow{4}{*}{$\begin{array}{l}\text { WEATHERED } \\
\text { BASEMENT }\end{array}$} & TOP & 19 & 5 & 11 & 9 & 4 & 4 & -- \\
\hline & BASE & - & 15 & - & - & 15 & 6 & -- \\
\hline & THICKNESS & - & 10 & - & - & 11 & 2 & -- \\
\hline & $\Omega \mathrm{m}$ & 179 & 266 & 222 & 219 & 312 & 189 & -- \\
\hline \multirow{4}{*}{$\begin{array}{l}\text { FRACTURED } \\
\text { BASEMENT }\end{array}$} & TOP & - & 15 & - & - & 15 & - & 1726 \\
\hline & BASE & - & - & - & - & - & - & - \\
\hline & THICKNESS & - & - & - & - & - & - & - \\
\hline & $\Omega \mathrm{m}$ & - & 10 & - & - & 22 & - & 940202 \\
\hline \multirow{4}{*}{ BASEMENT } & TOP & - & - & - & - & - & 6 & 126 \\
\hline & BASE & - & - & - & - & - & - & $17-$ \\
\hline & THICKNESS & - & - & - & - & - & - & $16-$ \\
\hline & $\Omega \mathrm{m}$ & - & - & - & - & - & 1000 & 10001000 \\
\hline
\end{tabular}

\subsubsection{Geoelectric Units}

The geoelectric sections (Figure 4a \& Figure 4b) show the variations of resistivity and thickness values of layers within the depth penetrated in the study area. Two traverses were taken along the NW-SE direction and one traverse along N-S direction. Five subsurface layers were revealed: Lateritic Topsoil, Sandy-clay, Weathered basement, Fractured basement and presumed Fresh basement.

\section{Topsoil}

The topsoil is relatively thin along these traverses. The average resistivity and thickness values for the topsoil are $178 \Omega \mathrm{m}$ and $1.0 \mathrm{~m}$ respectively.

\section{Sandy-clay}

Sandy-clay was encountered at shallow depths of 2.0meters on the average in six locations and the average resistivity and thickness values for the Clay are $23 \Omega \mathrm{m}$ and $7.0 \mathrm{~m}$ respectively.

\section{Weathered-basement}

Weathered-basement was encountered in six locations and the average resistivity and thickness values of the weathered-basement are $231 \Omega \mathrm{m}$ and $8.0 \mathrm{~m}$ respectively.

\section{Fractured-basement}

Fractured basement was encountered in four locations and the average resistivity and depth values to the top of fractured basement are $294 \Omega \mathrm{m}$ and $18.0 \mathrm{~m}$ respectively.

\section{Basement}

The basement is the fresh bedrock and is the last layer. It is relatively shallow in the study area, it was encountered in three locations and the average resistivity and depth values to the top of basement are $1000 \Omega \mathrm{m}$ and $11.0 \mathrm{~m}$ respectively.

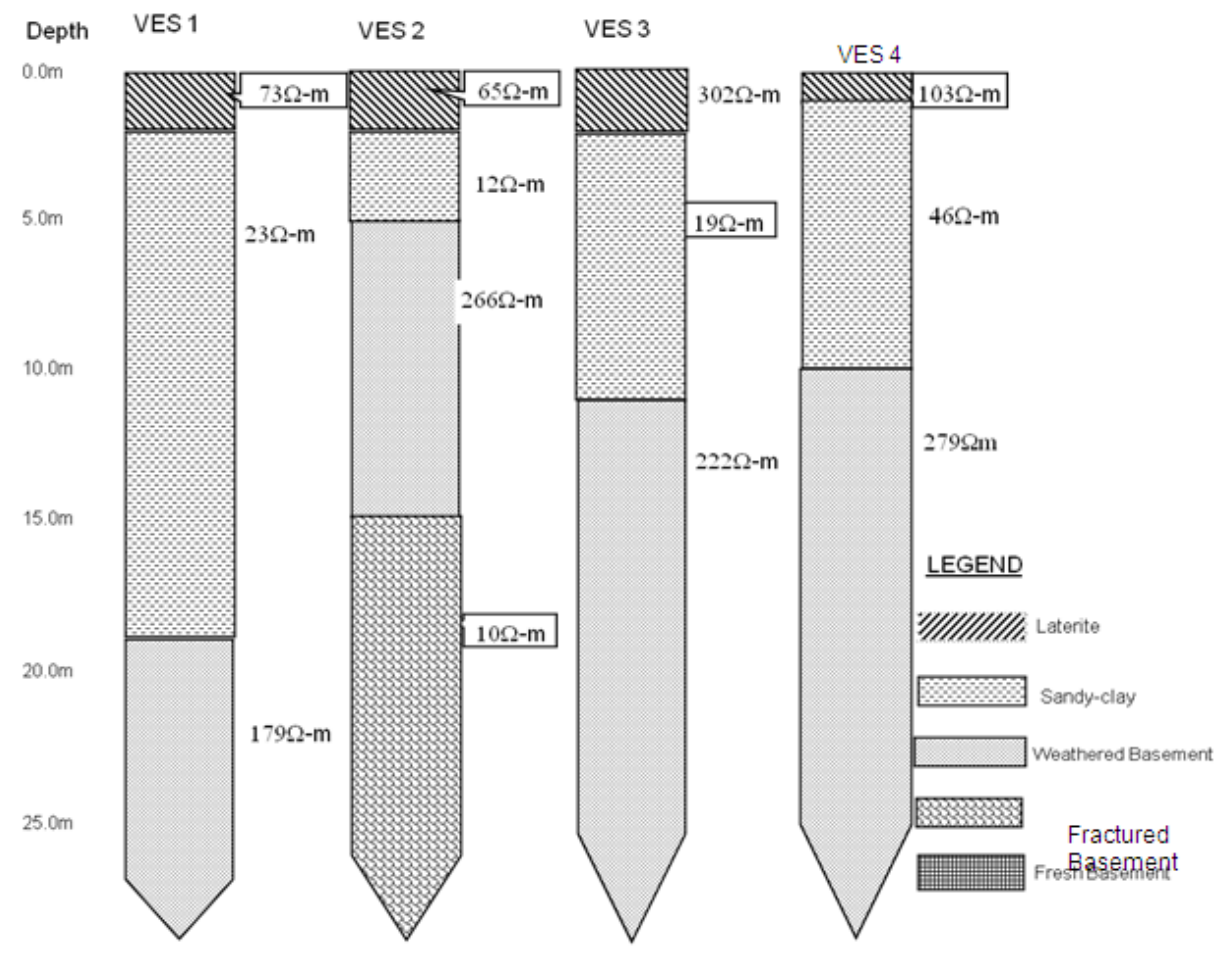

Figure 4a. Geoelectric sections of VES 1, 2, 3 \& 4 of college of engr. Abuad 


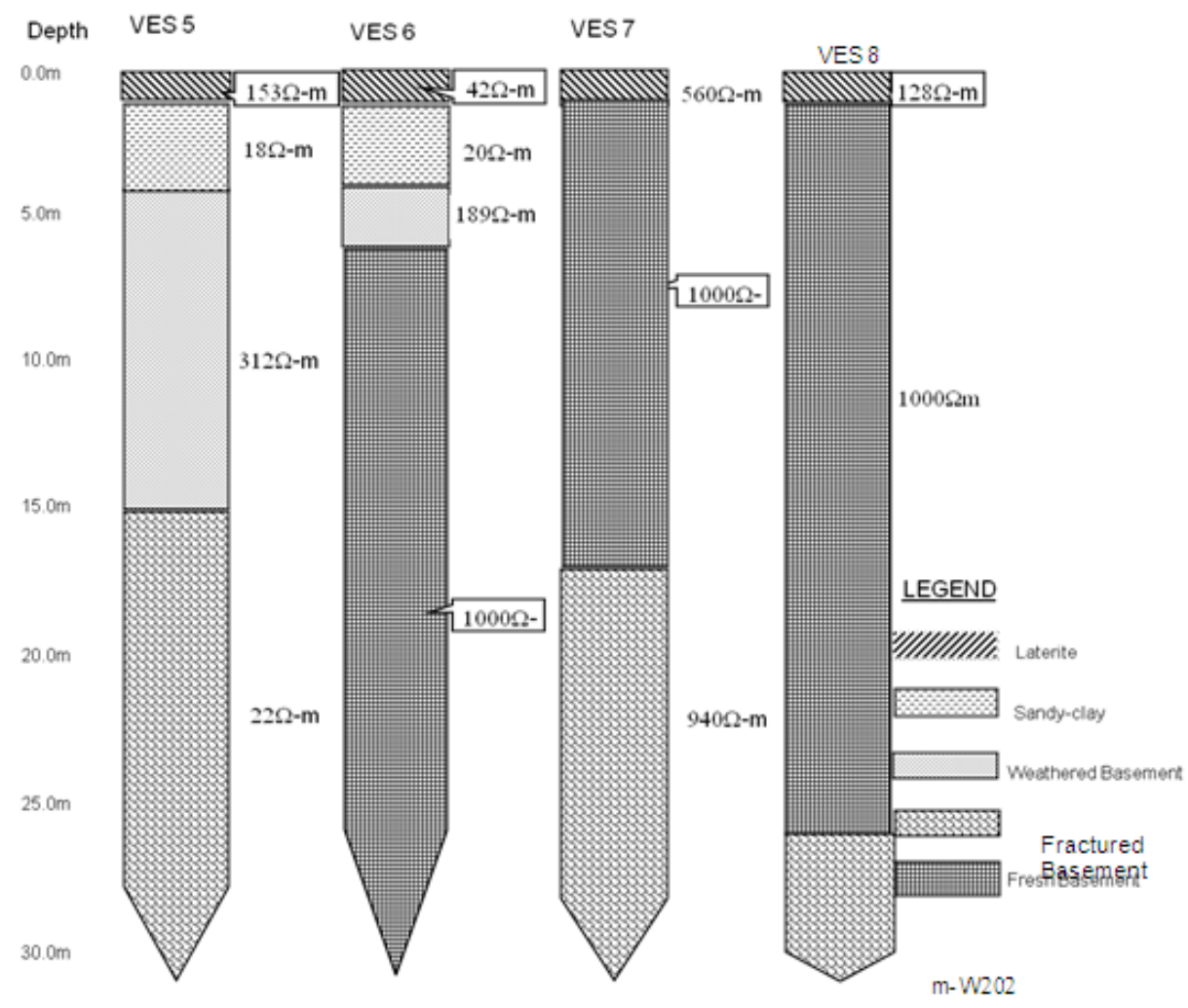

Figure 4b. Geoelectric sections of VES 5, 6, 7 \& 8 of college of engr. Abuad

\section{Overburden}

The overburden in assumed to include all materials above the presumably fresh basement. The depth to the bedrock varies from 1.0 to $26.0 \mathrm{~m}$ and the average depth to the bedrock is $11.0 \mathrm{~m}$ (Table 1 and Figure 4a \& Figure 4b). Overburden thickness was established in four locations and the average thickness value is $11.0 \mathrm{~m}$. The relatively moderate overburden thickness has potentials for groundwater saturation, however, the clayey nature and poor permeability of the materials will pose a challenge for water abstraction.

\subsection{Horizontal Profiling}

Result of the profiling carried out across one traverse section in NW-SE direction is presented in the section below. The traverse is 200meters long and is located right in front of the college. Four continuous subsurface lithologic units namely; Lateritic topsoil (blue), sandyclay (green), weathered basement (yellowish-brown) and fresh basement (reddish purple) were established by the profile section. A fractured zone (in between the fresh basement) was also revealed.

The result is presented in form of 2-D resistivity structures (Figure 5). The 2-D resistivity plot revealed a relatively thin overburden and shallow basement across the study area.
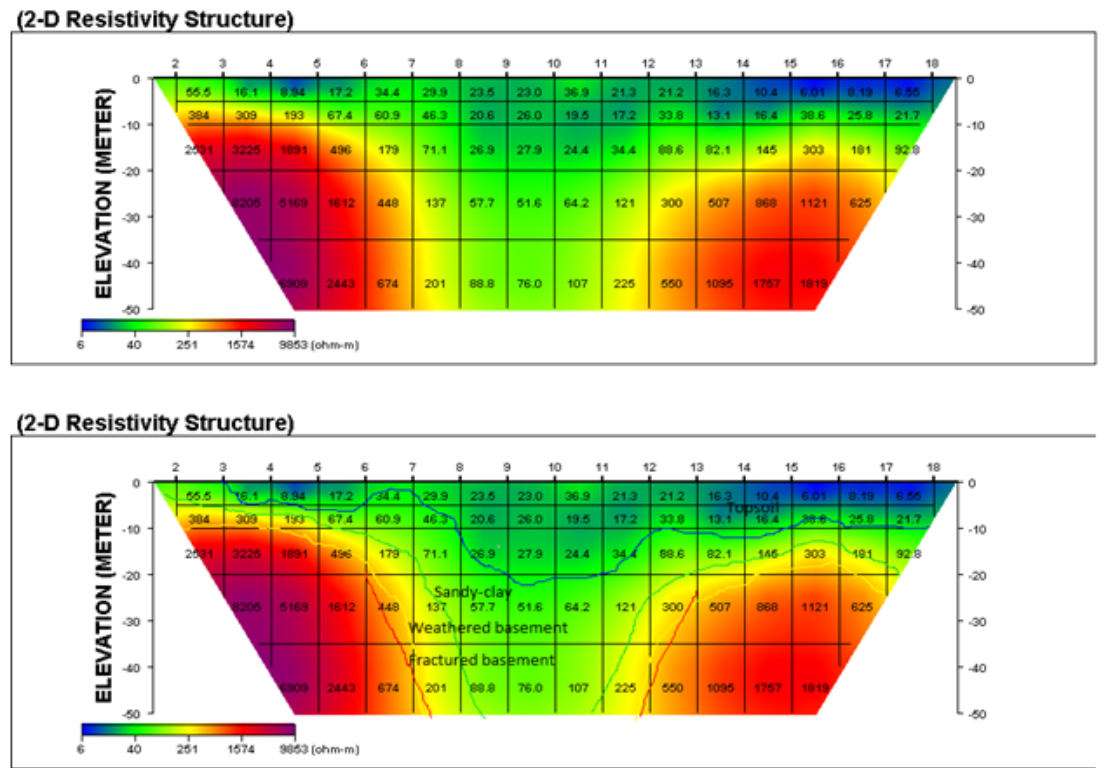

Figure 5. 2-D resistivity structures of the Profile 


\section{Evaluation of Groundwater Potential}

Given the average resistivity values and thicknesses of the sandy-clay, weathered and fractured basement layers and the overburden thickness, (Table 1 and Figure 4 \& Figure 5), the groundwater potential in the study area is rated as medium. The combination of overburden materials with the fractured basement constitutes aquiferous units within the study area although the sand and weathered/fractured basement units are largely responsible for the groundwater potential.

Observed thickness and nature of the weathered layer are important parameters in the groundwater potential evaluation of a basement complex terrain (Clerk, 1985; Bala and Ike, 2001). Horizon is regarded as a significant water-bearing layer (Bala and Ike 2001) if significantly thick and the resistivity parameters suggest saturated conditions. An average thickness value of $13 \mathrm{~m}$ and resisitivity of $127 \Omega \mathrm{m}$ of aquiferous unit and of low clay content is suggestive of a medium/moderate groundwater potential.

\section{Conclusions}

In this study, the groundwater potential of College of Engineering, Afe Babalola University, Ado-Ekiti, southwestern Nigeria was evaluated using profiling and eight Schlumberger vertical electrical soundings (VES). The curve types ranges between simple $\mathrm{K}, \mathrm{H}$ to complex $\mathrm{KH}, \mathrm{HA}$ and HK. The computer assisted profiling and sounding interpretation revealed five different subsurface lithologic sequences namely; lateritic topsoil, sandy-clay, weathered basement, fractured basement and, fresh basement. The topsoil, sandy-clay and weathered basement materials are characterised with relatively low resistivity values while the fresh basement materials are typified with high resistivity values. The combination of overburden materials with the fractured basement constitutes aquiferous units within the study area although the weathered basement and fractured basement units are largely responsible for the groundwater potential. The yield of the weathered basement material is dependent on the amount of the clay content. The higher the clay content, the lower the groundwater yield. The topsoil has limited hydrologic significance.

The groundwater potential rating of the area is considered moderate. Existing number of boreholes, storage facilities and reticulation network are inadequate for the ever-growing population of the university. There is need for proper completion and maintenance of borehole (s) and expansion of storage and reticulation facilities. An average depth of $40 \mathrm{~m}$ to $50 \mathrm{~m}$ is recommended for boreholes in this area. VES 2 \& VES 5 could be considered for drilling.

\section{References}

[1] Ademiluwa OL and Eluwole AB (2013) Hydrogeophysical Evaluation of the Groundwater Potential of Afe Babalola University Ado Ekiti, South-western Nigeria. Journal of Emerging trends in Engineering and Applied Sciences, Vol. 4 Issue 1 p 77

[2] Bala AE, Ike EC (2001). The aquifer of the crystalline basement rocks In Gusau area, Northwestern Nigeria. J. Min. Geol. 37 (2): 177-184.

[3] Clerk L (1985). Groundwater Abstraction from Basement Complex Areas of Africa. J. Eng. Geol., London 18: 25-34.

[4] Dutcher, L.C. and Garrett. A.A., 1963, Geologic and hydrologic features of the San Bernardino area, Califonia: U.S. Geological survey Water-Supply Paper 1419, 114 p.

[5] Ojo, J.S., Olorunfemi, M.O. and Falebita, D.E, An Appraisal of the Geologic Structure beneath the Ikogosi Warm Spring in SouthWestern Nigeria Using Integrated Surface Geophysical Methods. Earth Sciences Research Journal. 2011, 15 (1): 27-34.

[6] Oladipo, A. A., Oluyemi, E. A., Tubosun, I. A., Fasisi, M. K. and Ibitoye, F. I, Chemical Examination of Ikogosi Warm Spring in South Western Nigeria. Journal of Applied Sciences, 2005, 5 (1): 75-79

[7] Olayinka A. I. and Weller A. 1997. The inversion of geoelectrical data for hydrogeological applications in crystalline basement areas of Nigeria. Journ. Of Applied Geosciences, Vol. 37, Issue 2, June 1997, pp 103-105.

[8] Olayinka AI, Olorunfemi MO (1992). Determination of geoelectrical Characteristic in Okene Area and implication for boreholes setting. J. Min. Geol., 28: 403-412.

[9] Olorunfemi M. D. \& Olayinka A. I. (1992): Alteration of Geoelectric in Okene are and Implication for Borehole Sitting. Journal of Mining and Geology, pp. 403-411.

[10] Olorunfemi M. O. \& Oloruniwo M. A. (1985): Geoelectric Parameters and Aquifer Characteristics of Some Part of South Western Nigeria. Journal of Mining and Geology.

[11] Olorunfemi M. O. (1990): The Hydrogeological Implication of Topographic Variation with Overburden Thickness in Basement Complex. Area of South Western Nigeria. Journal of Mining and Geology. Vol. 26, No. 1.

[12] Olorunfemi MO, Fasuyi SA (1993). Aqufier types and geoelectric/hydrogeologic characteristics of part of central basement terrain of Nigeria (Niger State). J. Africa Earth Sci., 16 (3): 309-317.

[13] Olorunfemi MO, Olorunniwo MA (1985). Parameters and aquifer characteristics of some parts of SW. Nigeria Geologic Applica E. Hydrogeological, XX Part 1, pp. 99-109.

[14] Rehrl, C. and Birk, S. 2010, Hydrogeological Characterisation and Modelling of Spring Catchments in a Changing Environment. Austrian Journal of Earth Sciences Volume 103 Issue 2, p 106-117 Vienna.

[15] Talabi, A. O., 2013, Hydrogeochemistry and Stable Isotopes $(\delta 18 \mathrm{O}$ and $\delta 2 \mathrm{H})$ Assessment of Ikogosi Spring Waters. American Journal of Water Resources, 2013, Vol. 1, No. 3, 25-33. 